\title{
Alleviation of learned helplessness following septal lesions in rats
}

\author{
GWYNETH H. BEAGLEY and WALTER K. BEAGLEY \\ Emory University, Atlanta, Georgia 30322
}

\begin{abstract}
Rats subjected to inescapable shock subsequently were found to be helpless, unable to escape shock in an FR3 leverpress escape test. Rats which received equal amounts of escapable shock were unimpaired in their ability to escape, performing as well as controls given no pretest shock. One-half of the rats in each training group were then given bilateral lesions in the septal area, and all rats were retested. The lesions produced a large improvement in escape responding in the helpless group, but not in either of the nonhelpless groups. The results of this study suggest that septal lesions eliminate response inhibition caused by learned helplessness.
\end{abstract}

If animals receive a series of painful electric shocks from which they are unable to escape, they become impaired in their ability to learn an escape response during subsequent shock. This was studied in dogs by Overmier and Seligman (1967), who called the phenomenon learned helplessness. It has since been demonstrated in cats and in rats (Looney \& Cohen, 1972; Maier, Albin, \& Testa, 1973; Seligman \& Beagley, 1975).

One striking characteristic of this phenomenon is the passivity of the helpless animal's behavior. $\mathrm{He}$ quietly accepts the shock without the normal vocalization, running, or jumping. This subdued state resembles that produced in cats by electrical stimulation of the septum. Beagley (1972) and Siegel and Skog (1970) found that septal stimulation could suppress attack, rage, or fear reactions. It is possible, therefore, that the passive behavior of a helpless animal might be under the control of behavioral inhibition from the septum. Evidence for septal involvement in helplessness comes from work by Thomas and Balter (cited in Seligman, 1975), who eliminated learned helpless behavior in cats by injecting atropine, a cholinergic blocker, directly into the septum.

This study tests whether septal lesions will cure rats of a previously acquired learned helplessness.

\section{METHOD}

\section{Subjects}

The subjects were 30 male albino Sprague-Dawley strain rats obtained from Charles River Breeding Laboratories. After their arrival, they were housed individually for at least 2 weeks before being run in the experiment. They were kept on a 12:12 light-dark cycle, and given ad-lib food and water.

Supported in part by a grant from the Emory University Research Committee. Requests for reprints should be addressed to Walter K. Beagley, Department of Psychology, Alma College, Alma, Michigan 48801.

\section{Apparatus}

Two $40 \times 20 \times 27 \mathrm{~cm}$ high test chambers were used for training and testing. The chambers were made of plywood and Plexiglas and had a floor of .5-cm-diam stainless steel bars. Each chamber was equipped with a removable metal barrier, $5.5 \mathrm{~cm}$ high, which could be placed across the center of the cage. Each chamber also had a removable lever, $5 \mathrm{~cm}$ wide, projecting $6 \mathrm{~cm}$ into the cage, $8 \mathrm{~cm}$ above the floor. This way the chambers could be used either as shuttleboxes or leverpress chambers. Shock was produced by two BSR-LVE Sg 904/113-02 shockers. It was delivered through safety pin electrodes mounted subcutaneously in the upper back of each rat, with the floor acting as ground (Seligman \& Beagley, 1975). Shock intensity was $1 \mathrm{~mA}$.

\section{Procedure}

Animals were run in triads. For the training procedure, each triad consisted of an animal able to escape the training shock (escape group), an animal which received shock equal to the escapable partner but which could not himself escape the shock (helpless group), and a naive animal (control group) which received no training shock but started directly in the testing part of the experiment.

Training of the escape group $(n=10)$ was conducted with the barrier in place and without the lever. Fifty trials of shock were given. The animal could turn off the shock by jumping the barrier twice. If the animal did not escape, the trial lasted $30 \mathrm{sec}$ and then terminated automatically. The experimenter recorded the latency from shock onset to escape (or automatic 30-sec termination) with a stopwatch. The intertrial interval varied from 60 to $120 \mathrm{sec}$, $\mathbf{M}=90 \mathrm{sec}$.

The training of the helpless group $(n=10)$ consisted of delivery, to each rat, of shock in exactly the same pattern as its escape group partner received. This was accomplished by wiring together the shock sources. The barrier was present in the chamber of the helpless animal, but jumping it had no effect.

The naive controls $(n=10)$ were given no training or pretesting experience in the experimental chamber.

Testing procedure for all three groups was identical and was carried out $24 \mathrm{~h}$ after training, in the same chamber. The barrier was removed, but the barpress lever was present. Testing consisted of 20 trials of escapable shock. The shock lasted $60 \mathrm{sec}$ if no successful escape was made. Leverpresses were counted automatically by a BSR-LVE predetermining counter and shock was automatically shut off by the third leverpress. Intertrial intervals ranged from 60 to $120 \mathrm{sec}, M=90 \mathrm{sec}$.

Each of the three groups was then divided, and half of the animals from each of the three training conditions underwent surgery $24 \mathrm{~h}$ after the test. 
The animals were anesthetized with sodium pentobarbital, and placed in the stereotaxic instrument with the incisor bar raised $5 \mathrm{~mm}$ above the interaural line (de Groot, 1959). They were given bilateral septal lesions $7.6 \mathrm{~mm}$ anterior and $\pm .8 \mathrm{~mm}$ lateral from earbar zero, and $5.5 \mathrm{~mm}$ down from the skull surface. The lesions were made by passing an anodal dc current of $2.5 \mathrm{~mA}$ for $25 \mathrm{sec}$ between the electrode and ground on the incisor bar. The animals were allowed 1 week for recovery from the operation before being given a second test with the leverpress escape procedure. The nonlesioned animals were also given a second test after a corresponding lapse of time.

Following the completion of testing, all operated animals were perfused with physiological saline, fixed with $10 \%$ Formalin, and frozen brain sections $50-\mu$ thick were cut and examined to verify the location of the lesions.

\section{RESULTS}

\section{Training}

All 10 rats in the escape group learned the double shuttle response, performing a mean of 41.3 successful $(<30 \mathrm{sec})$ escapes for 50 trials. The 10 pairs of escape and helpless rats received a mean total of $725.2 \mathrm{sec}$ of shock during the training session.

\section{First Test}

On the first exposure to the leverpress escape, the animals in the escape and control groups learned quickly enough to make an average of 12.5 successful $(<60 \mathrm{sec})$ escapes in 20 trials. The helpless animals failed to learn the task and averaged only 2.5 escapes. Comparisons of escape latencies (see Figure 1) showed

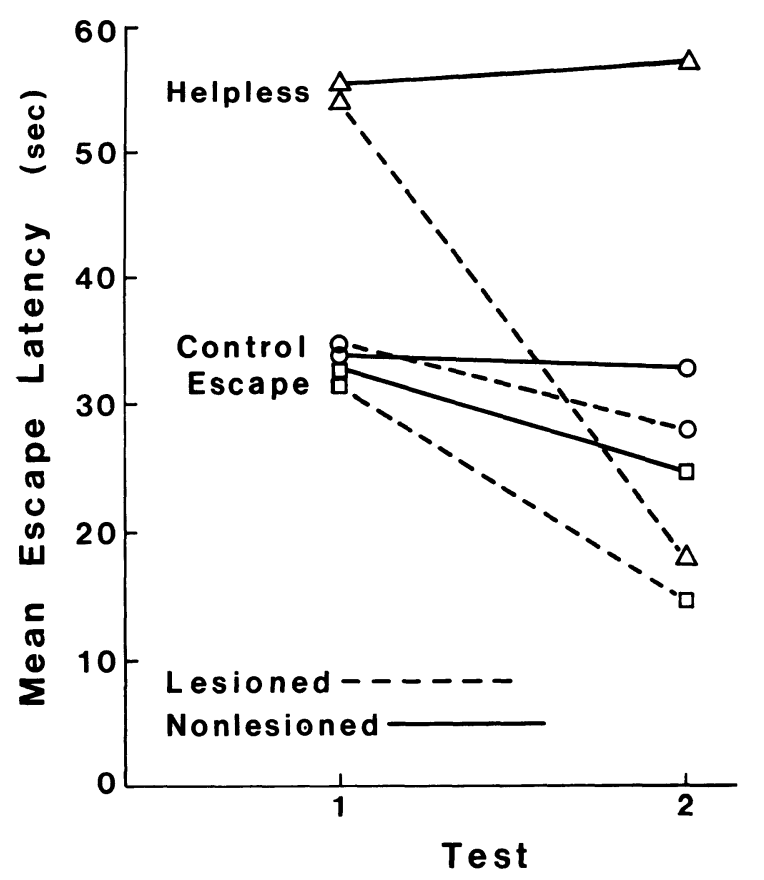

Figure 1. Mean latencies for leverpress escape tests. Half of the rats from each group were lesioned between Test 1 and Test 2. Lesions produced significant improvement only in helpless animals. that helpless animals took significantly longer to escape than either their escape partners or control animals ( $\mathrm{n}=10, \mathrm{p}<.01$, Walsh test, two-tailed) (Siegel, 1956).

\section{Second Test; Postlesion}

The helpless animals that were lesioned showed a highly significant improvement from the first to the second test $[U(100,100)=742, p<.0001$, MannWhitney $U$, two-tailed]. The mean number of successful escapes increased from 3 to 19 and the mean latency to escape decreased from 54.1 to $18.0 \mathrm{sec}$ (Figure 1). The unlesioned helpless animals showed no change from the first test. While the escape and control groups showed slight improvement (decreases in escape latency), lesioned animals did not show greater improvement than unlesioned.

\section{Histology}

All 15 rats had bilateral lesions destroying large sections of the anterior septal nuclei. Twelve of the 15 rats also showed significant damage to the medial septum. Damage to nonseptal structures was small and varied from rat to rat, including some cortex, corpus callosum, anterior hippocampus, and superior fornix. The lesions consistently extended from the lateral ventricles to the midline and from the corpus callosum down into the medial septum. Along the anterior-posterior continuum, the lesions can be divided into two groups; representative lesions from each group are shown in Figure 2. For the first group $(n=7)$, maximum damage occurred in the most anterior portion of the lateral septum and medial septum, anterior to where the corpus callosum crosses the midline. The second group $(n=8)$ has maximum damage about $1,000 \mu$ posterior to the first. The two lesion groups were distributed evenly among the three training conditions, and there is no correlation between location of maximum damage and behavior.

\section{DISCUSSION}

The main result of this study is that septal lesions abolished learned helplessness. This finding is reinforced by the following two points.

First, the helplessness produced was severe and long lasting. The failure of the unlesioned helpless animals to improve on the second test shows that time does not alleviate helplessness in rats as it does in dogs (Overmier \& Seligman, 1967). Although the escape group rats received the same amount of shock as the helpless animals, they escaped reliably on both tests. This shows that the severity of the helplessness is not simply a result of painful shock but, as Seligman (1975) has emphasized, depends on the animal's inability to control the shock.

Second, the septal lesions eliminated the entire syndrome. Lesioned helpless animals not only escaped as 

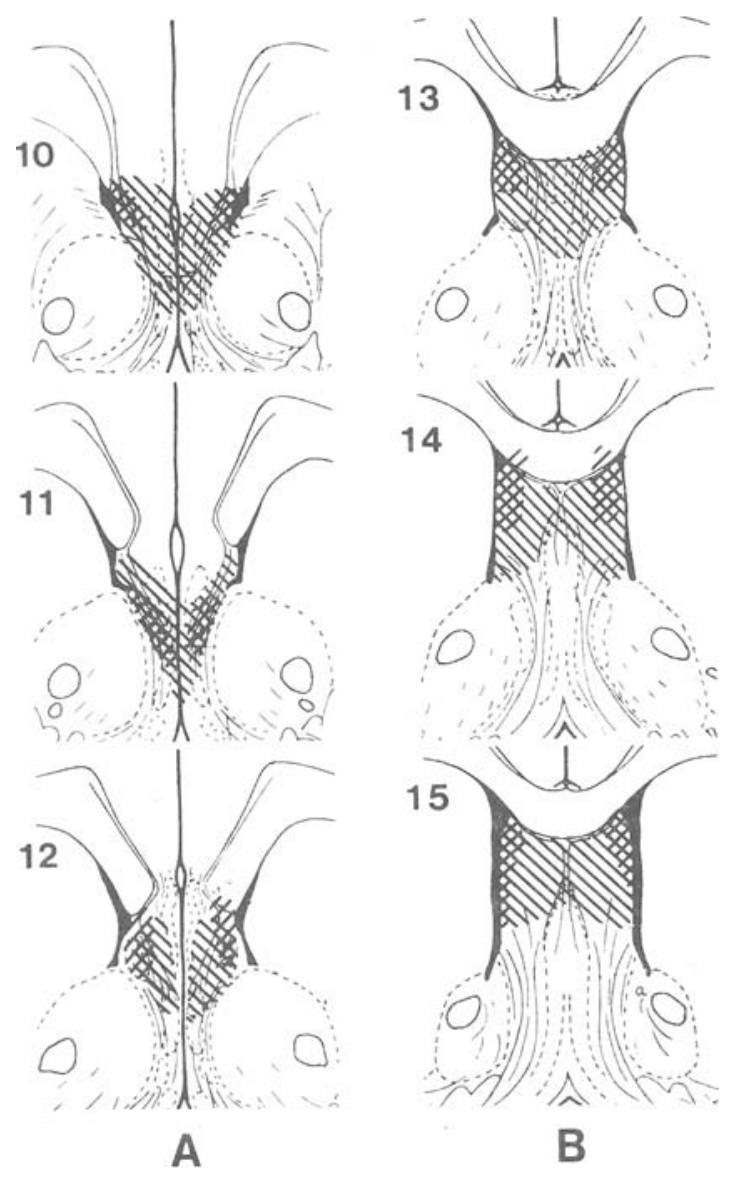

Figure 2. Representative septal lesions. (A) Anterior septum, $\mathrm{n}=7$. (B) Midseptum, approximately $1 \mathrm{~mm}$ posterior to $\mathbf{A}$, $n=8$. Diagonal lines indicate both the smallest and largest lesions observed for each section. Numbers refer to plates in König and Klippel's (1974) Rat brain atlas.

quickly as the escape and control groups, but also appeared normal. They were no longer passive and unemotional while receiving shock. That these effects were really due to the septal lesions was confirmed by a supplementary testing of two helpless animals exposed to the surgical procedure, but with no lesion. Neither their escape behavior nor their passive appearance was affected.

The remaining question of interest is why septal lesions cure learned helplessness. As the escape and control groups were unaffected by lesions, it is unlikely that the lesions cause a nonspecific facilitation of leverpress escape. It could be argued that the escape and control groups might already have been performing at or near a performance ceiling and thus were incapable of showing postlesion improvement. This is probably not the case. On the first test, mean escape latencies for these groups is greater than $30 \mathrm{sec}$. Even on the slightly improved second test, only two animals escaped with latencies consistently shorter than $10 \mathrm{sec}$. Instead of making three quick leverpresses, the rats typically spent considerable time engaged in other defensive behaviors: jumping around and vocalizing.

Thus the escape and control groups have difficulty responding quickly because of competing responses. The difficulty is not alleviated by the lesions. This suggests that septal lesions improve escape performance primarily in animals which have inhibited all responding, not in animals which suffer from competing response tendencies.

This is reinforced by Thomas and McCleary (1974), who demonstrated that active avoidance responding is best facilitated by septal lesions in situations such as two-way shuttle avoidance where the animal is normally inhibited from reentering the shock compartment, and one-way shuttle made unpleasant by the addition of a water barrier. Both situations involve conflict, not between competing responses, but between responding and not responding. Septal lesions release animals from this type of inhibition.

In contrast, tasks that involve competing response tendencies such as reversal of position habit (Hamilton, 1970; Zucker \& McCleary, 1964) or reversal of discrimination learning (Schwartzbaum \& Donovick, 1968) are typically either made worse or are unaffected by septal lesions.

Thus the effect of septal lesions on learned helplessness appears to be explainable in terms of McCleary's (1961) theory of septal response inhibition. Whether the acquisition of learned helplessness can be characterized in the same terms is not yet clear. Thomas (Note 1) has suggested that helplessness might consist of an animal's learning to use massive inhibition as a form of internal protection from trauma. Lesioning the septum may prevent this inhibition and force the animal back into an active defense.

\section{REFERENCE NOTE}

1. Thomas, E. Personal communication, March 29, 1973.

\section{REFERENCES}

BEAGLEY, G. Septal facilitation and inhibition of responses elicited from subcortical structures in the cat. Unpublished Master's dissertation, Bryn Mawr College, 1972.

DEGRoot, J. The rat forebrain in stereotaxic coordinates. Amsterdam: Verhandelingen de koninklijke Nedelandse Akademie van Wetenschappen, 1959.

Hamilton, L. W. Behavioral effects of unilateral and bilateral septal lesions in rats. Psychology and Behavior, 1970, 5, 855-859.

KönIG, J. F. R., \& KLIPPEL, R. A. The rat brain. Huntington, New York: Robert E. Kneger, 1974.

LOONEY, T. A., \& Cohen, P. S. Retardation of jump up escape responding in rats pretreated with different frequencies of noncontingent electric shock. Journal of Comparative and Physiological Psychology, 1972, 78, 317-322. 
Maier, S. F., Albin, R. W., \& Testa, T. J. Failure to learn to escape in rats previously exposed to inescapable shock depends on the nature of the escape response. Journal of Comparative and Physiological Psychology, 1973, 85, 581-592.

MCCleARY, R. A. Response specificity in the behavioral effects of limbic system lesions in the cat. Journal of Comparative and Physiological Psychology, 1961, 54, 605-613.

Overmier, J. B., \& Seligman, M. E. P. Effects of inescapable shock upon subsequent escape and avoidance learning. Journal of Comparative and Physiological Psychology, 1967, 63, 23-33.

Schwartzbaum, J. S., \& Donovick, P. J. Discrimination reversal and spatial alternation associated with septal and caudate dysfunction in rats. Journal of Comparative and Physiological Psychology, 1968, 65, 83-92.

Seligman, M. E. P. Helplessness. San Francisco: Freeman, 1975.

Seligman, M. E. P., \& Beagley, G. Learned helplessness in the rat. Journal of Comparative and Physiological Psychology, 1975, 88, 534-541.

Siegel, A., \& SKog, D. Effects of electrical stimulation of the septum upon attack behavior elicited from the hypothalamus in the cat. Brain Research, 1970, 23, 371-380.

SIEgel, S. Nonparametric statistics for the behavioral sciences. New York: McGraw-Hill, 1956.

Thomas, J. B., \& McCleary, R. A. One-way avoidance behavior and septal lesions in the rat. Journal of Comparative and Physiological Psychology, 1974, 86, 751-759.

ZuCKer, I., \& MCCleary, R. A. Perseveration in septal cats. Psychonomic Science, 1964, 1, 387-388.

(Received for publication April 14, 1977; revision accepted December 21, 1977.) 